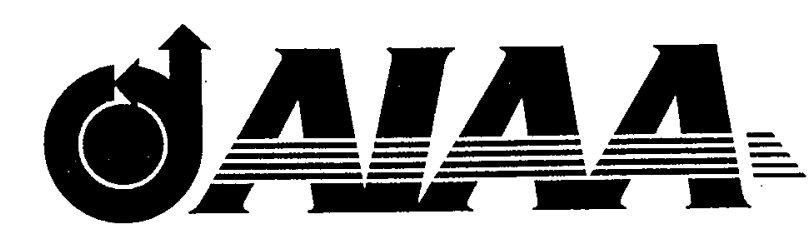

NASA-TM-112838

\title{
AIAA 97-1589
}

Inlet Shape Effects on the Far-Field Sound of a Model Fan

L. R. Clark

NASA Langley

Hampton, VA

R. H. Thomas

Virginia Tech, VCES

Hampton, VA

R. P. Dougherty

Boeing Commercial Airplane Group

Seattle, WA

F. Farassat and C. H. Gerhold

NASA Langley

Hampton, VA

\section{3rd AIAA/CEAS Aeroacoustics Conference May 12 - 14, 1997 / Atlanta, GA}




\section{-}




\title{
INLET SHAPE EFFECTS ON THE FAR-FIELD SOUND OF A MODEL FAN
}

\author{
L. R. Clark ${ }^{\dagger}$ \\ Aeroacoustics Branch \\ NASA Langley Research Center, MS 461 \\ Hampton, VA 23681 \\ R. H. Thomas ${ }^{\dagger \dagger}$ \\ Mechanical Engineering Department, Virginia Tech \\ VCES, 303 Butler Farm Road, Suite 101, Hampton, VA 23666 \\ R. P. Dougherty* \\ Noise Research, Boeing Commercial Airplane Group \\ Mail Stop 67-ML, P.O. Box 3707, Seattle, WA, 98124-2207 \\ F. Farassat ${ }^{* *}$ and C. H. Gerhold ${ }^{\S}$ \\ Aeroacoustics Branch \\ NASA Langley Research Center, MS 461 \\ Hampton, VA 23681
}

\begin{abstract}
$\underline{\text { Abstract }}$
A wind tunnel test was conducted to determine the effects of inlet shape on fan radiated noise. Four inlet geometries, which included a long standard flighttype inlet, a short, aggressive flight inlet a scarf inlet, and an elliptical inlet were investigated in the study. The fan model used in the study was a 0.1 scale of the Pratt and Whitney Advanced Ducted Propeller (ADP), an ultra high bypass ratio turbofan engine. Acoustic data are presented for a fan speed of $70 \%(12,000 \mathrm{rpm})$ and a tunnel speed of 0.10 Mach number. The fan was configured with a 16-bladed rotor and a 40 stator vane set that were separated by 2.0 chord lengths. The radiated noise was measured with 15 microphones on a boom that traversed the length of the tunnel test section. Data from these microphones are presented in the form of sideline angle directivity plots. Noise associated with the test inlets was also predicted using a ray acoustics code. Inlet shape has been found to have a significant effect on both tone and broadband noise, and
\end{abstract}

\footnotetext{
${ }^{\dagger}$ Aerospace Engineer

${ }^{\dagger \dagger}$ Research Assistant Professor, Senior Member AIAA

* Principal Engineer, Member, AIAA

"* Sr. Research Scientist, Associate Fellow, AIAA

${ }^{\S}$ Sr. Research Engineer, Member, AIAA
}

the non-axisymmetric inlet shape can be used for a noise reduction method.

\section{$\underline{\text { Introduction }}$}

Various inlet geometries have been studied over the years as a means of reducing noise radiated from fans and ducts. ${ }^{1-4}$ These studies showed that inlet shape can have a significant impact on inlet noise level and directivity. Much of the earlier work involved inlets that were used to direct upward noise that would normally propagate to the underside of the inlet. These devices, commonly called scarf inlets, have the lower side extended forward. They make possible a passive approach to inlet noise control through noise redirection instead of noise suppression.

In a wind tunnel test conducted by $\mathrm{Abbott}^{1,2}$ a scarf-type inlet called a scoop inlet provided a maximum noise reduction of 12 to 15 decibels below the inlet for throat Mach numbers ranging from 0.31 to 0.70 . Also, a recent numerical study by Peake ${ }^{4}$ suggests that at high frequency the effects of scarfing on the far field can be

Copyright () 1997 by the American Institute of Aeronautics and Astronautics, Inc. No copright is asserted in the United States under Title 17, U.S. Code. The U.S. Government has a royalty-free license to exercise all rights under the copyright claimed herein for government purposes. All other rights are reserved by the copyright owner. 
even greater, with noise reductions in one particular direction of as much as $20 \mathrm{~dB}$ for modes close to cutoff. A scarf inlet was one of two non-axisymmetric configurations tested in the present study.

An elliptical inlet was also tested in the present investigation. A nonaxisymmetric inlet sometimes dictated by aircraft engine installation requirements such as ground clearance. The purpose for the elliptical inlet was to redirect the attendant noise in a beneficial way and satisfy the additional requirement of ground clearance, for example. More specifically, the goal was to determine if noise associated with the inlet could be focused along the axis of the inlet. Test data obtained with both the scarf and elliptical inlets are compared to two axisymmetric flight-type inlets of different lengths. One of the flight inlets had a conventional design; the other had a more aggressive, shorter length, design.

When compared with acoustically treated engine nacelles that are in common use today, the potential advantage of non-axisymmetric inlets is obvious. Because they are structurally simpler, they could be very attractive noise control devices, if they could be used to attain the same level of inlet noise reduction that is possible with acoustic treatment. The purpose, then, of this paper is to expand, further the understanding of how fan inlets of different shapes perform in a simulated flight environment.

\section{Description of Fan Model}

The fan model is a single-stage fan. A cross section of the fan and cowl are shown in Figure 1. The fan is a 16 wide-chord-blade rotor $12.000 \pm 0.002$ in $(30.48 \pm .005 \mathrm{~cm})$ in diameter (D) followed by a single stator row. The rotor blades and stators are based on the Pratt and Whitney 17-Inch ADP design. The rotor blades are 3.33 in $(8.46 \mathrm{~cm})$ in span with a hub-to-tip ratio of 0.445 . The chord at the tip is 2.43 in $(6.17$ $\mathrm{cm}$ ). In scaling from the 17- to 12-Inch model the tip speed was held constant; therefore, the $100 \%$ design speed is $17188 \mathrm{rpm}$ giving a tip speed of $905 \mathrm{ft} / \mathrm{s}(276$ $\mathrm{m} / \mathrm{s}$ ). The blade angle setting is for the takeoff condition which is close to the landing condition. The fan pressure ratio is 1.27 at $100 \%$ speed. $^{5}$

There are 40 fan exit stator vanes in the normal model configuration. This fan model allows for interchangeable stator vane sets and a set of 20 vanes was tested. In reducing the stator van number from 40 to 20 no attempt to retain solidity was made. The model design also allows for rotor-stator spacing in three increments through the use of spacers. The spacing is the distance from the fan blade trailing edge to the vane leading edge using the fan mid-span chord.
Spacings allowed are 1.0,1.5, and 2.0 which are referred to as a forward (FWD), mid, and aft (AFT) spacing, respectively. More details of the fan are reported in Reference 6.

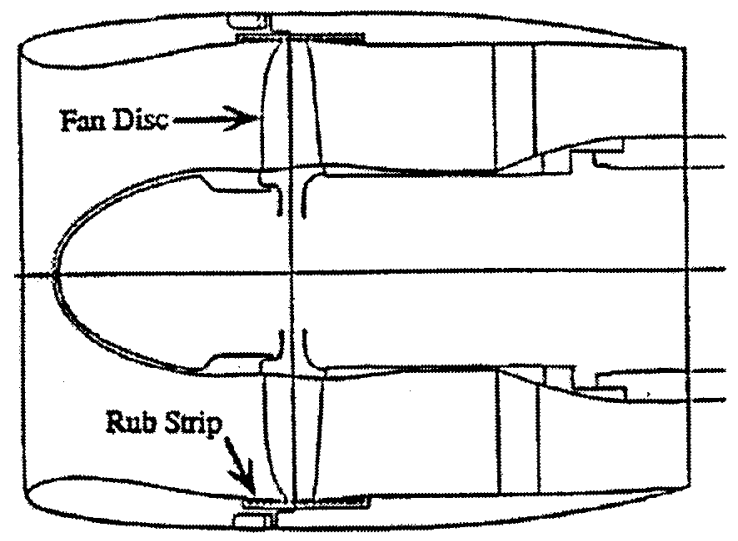

Figure 1. Schematic of the 12-inch fan, stator vanes are shown in the aft position.

\section{Description of Wind Tunnel}

All tests were conducted in the NASA Langley $14 \times 22$-Foot $(4.3 \times 6.7-\mathrm{m})$ Subsonic Wind Tunnel. ${ }^{7}$ This tunnel is a closed circuit, single return, atmospheric wind tunnel which has an open or a closed test section. All tests were conducted in the open test section configuration, seen in a top view in Figure 2. When closed, the test section is $14.5 \mathrm{ft}(4.4 \mathrm{~m})$ high by $21.75 \mathrm{ft}(6.6 \mathrm{~m})$ wide by $50 \mathrm{ft}(15.2 \mathrm{~m})$ long. In the open configuration the side walls and ceiling are raised to a height of $24.5 \mathrm{ft}(23.5 \mathrm{~m})$ and the collector is open to $34.5 \mathrm{ft}(10.5 \mathrm{~m})$ wide. The test section is within a chamber which is $61.6 \mathrm{ft}(18.8 \mathrm{~m})$ high by $77 \mathrm{ft}(25.0$ m) wide by $82 \mathrm{ft}$ long. The walls of the chamber are lined with acoustic foam. The fan was installed on the aft model cart, the center of which is $40 \mathrm{ft}(12.2 \mathrm{~m})$ downstream of the nozzle. A mast at the center of the cart supports the model sting which is $8 \mathrm{ft}(2.4 \mathrm{~m})$ long so that the center of the fan is located $32 \mathrm{ft}(9.8 \mathrm{~m})$ from the beginning of the test section. A photograph, looking downstream, of the fan installed in the test section is shown in Figure 3. The model centerline was normally at a height of $6.5 \mathrm{ft}(2.0 \mathrm{~m})$ above the tunnel floor, or $0.75 \mathrm{ft}(0.23 \mathrm{~m})$ below the tunnel centerline.

Additional acoustic treatment was applied to the tunnel test section for this test. The ceiling and that portion of the floor of the test chamber that is out of the flow were covered with sheets of 6-in $(15.2-\mathrm{cm})$ thick open cell foam. Other wall surfaces that were not already lined and were outside of the flow were covered with acoustic wedges, 4 in $(10.2 \mathrm{~cm})$ thick. The floor of 
the test section was composed of two-foot thick acoustic wedges made from $6.0-\mathrm{lb} / \mathrm{ft}^{3}\left(16-\mathrm{kg} / \mathrm{m}^{3}\right)$ density

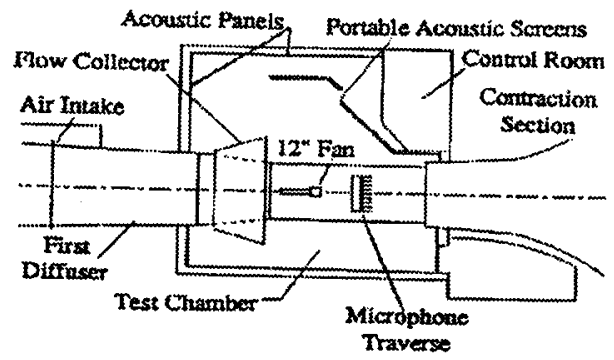

Figure 2. Top view of the 14 by 22 -Foot Subsonic Tunnel test section with 12-inch fan in position. ${ }^{7}$ The microphone wing could traverse the length of the test section to the fan. Flow is from right to left.

polyurethane foam. The wedges were filled in with low density foam to form a flat surface. The surface of the foam floor can be seen in the photograph, Figure 3.

Also shown in Figure 3 is the microphone traverse wing. The wing is airfoil shaped to reduce selfnoise and is covered with foam. The probe mounted on top of the wing is used to measure wind tunnel turbulence levels. It was removed prior to taking acoustic measurements. The wing nearly spans the test section and rides on two tracks each with a stepper motor. Both motors are driven by a common command sequence which provides precise positioning. The microphone wing was normally traversed in a plane $4 \mathrm{ft}$ below the model centerline.

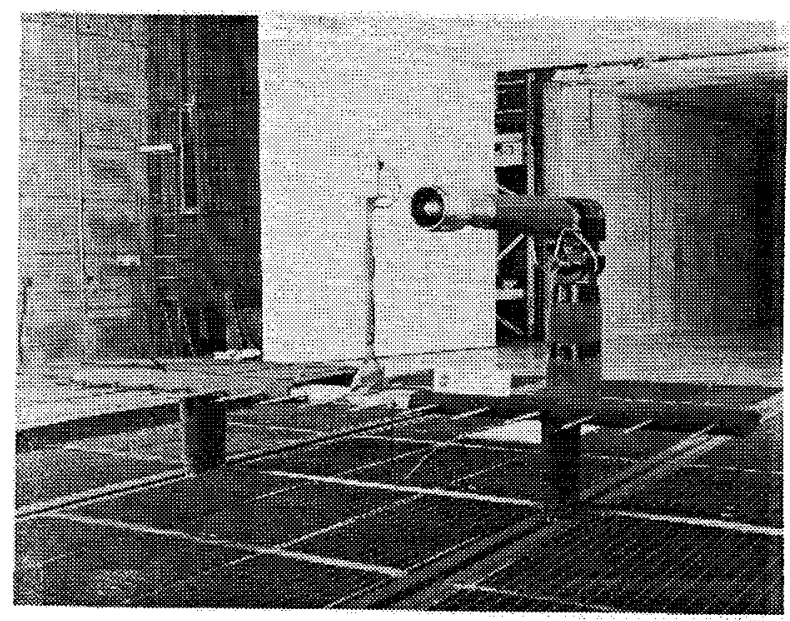

Figure 3, Photograph looking downstream, of the 12-inch fan installed in the 14 by 22-Foot Tunnel with microphone traverse in the foreground.

\section{$\underline{\text { Instrumentation }}$}

Far-field acoustic data were measured using the 15 microphones on the traversing wing of Figure 3. The microphones were $1 / 4$-in $(0.64-\mathrm{cm})$ Brüel \& Kjær condenser microphones. The microphones were laboratory calibrated and found to have a flat frequency response to within $\pm 2.0 \mathrm{~dB}$ out of $10 \mathrm{kHz}$ and to within $\pm 9 \mathrm{~dB}$ out of $25 \mathrm{kHz}$. These laboratory calibrations were used in the data reduction. Each microphone was oriented upstream and fitted with an aerodynamic nose cone to minimize self noise. The microphones were field calibrated at the beginning and end of each day. Signals were passed through a preamplifier to a multiple channel amplifier which is on the traverse. The amplified signals were high and low pass filtered before being digitized at $62.5 \mathrm{kHz}$ and stored. A total of 2 seconds of data was collected.

Tunnel temperature and pressure as well as atmospheric conditions were collected by the tunnel data acquisition system sampling at $1 \mathrm{~Hz}$. Tunnel Mach number was calculated and the tests were run at fixed tunnel Mach numbers. Separate aerodynamic runs were made with four rakes inserted in the fan exhaust. The rakes were equally spaced and located at $1.17 \mathrm{D}$ behind the rotor. These mean flow data were also acquired by the tunnel data acquisition system.

\section{Test Program}

The major parameters varied in the test program included tunnel speed, model speed and inlet shape. The tunnel speed included a no-flow test and Mach numbers of 0.05 and 0.10 . Mach number of 0.05 is just above the minimum forward velocity required to remove inflow distortions. ${ }^{8}$ At each tunnel Mach number the model was run at 70,90 , and $100 \%$ corrected speed. However, in this paper, only results at $70 \%$ speed are shown. These tunnel and model speed variations were made for the one major model configuration, 40-stator-vane sets at a rotor-stator spacing of 2.0 chords (AFT).

For each combination of vane set and location and tunnel and model speed the microphone traverse wing collected data at 18 axial stations in the test section. The stations ranged from $X=22.7 \mathrm{D}$ upstream of the fan to $-3.36 \mathrm{D}$ (downstream of the fan) and the microphone traverse nearly spanned the test section from $Y=-7.5 \mathrm{D}$ to $7.5 \mathrm{D}$. The origin of the coordinate system is on the engine axis at the rotor mid-chord location. The coordinate system is shown schematically in Figure 4. Station 1 is the farthest upstream location with station 14 being under the fan at $\mathrm{X} / \mathrm{D}=0$. This traverse, of the microphone wing results 3

American Institute of Aeronautics and Astronautics 
in 255 microphone locations, most within $10.0 \mathrm{D}$ of the fan. The sideline or polar angle, $\theta$ (with respect to the engine axis), covered by the traverse is from about $6^{\circ}$ to about $140^{\circ}$. At station 14 , where all 15 microphones are in the same azimuthal plane and can be corrected for distance to the same radius from the axis, the range in azimuthal angle, $\alpha$, is from $-68^{\circ}$ to $+68^{\circ}$.
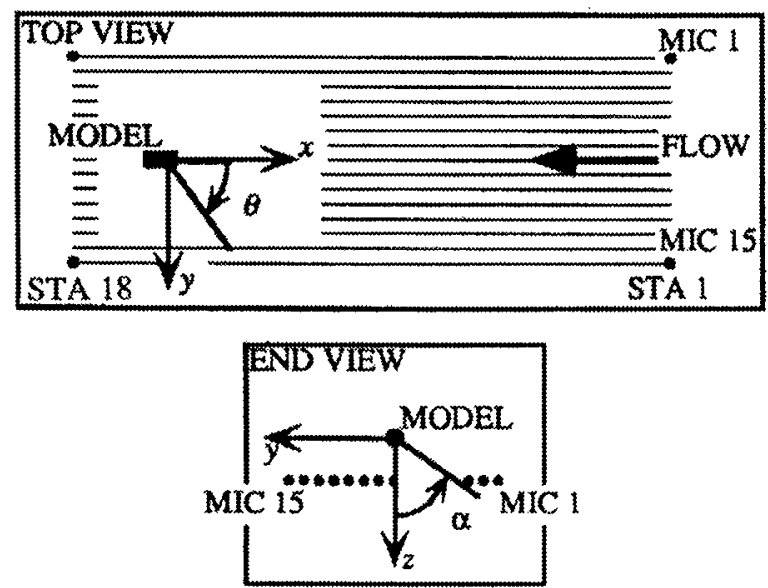

Figure 4. Top view and end view (looking downstream) of fan model showing relative positions of the microphones, axial measurement stations, and coordinate system.

\section{Description of Inlet Configurations}

Two baseline inlets were tested in the present study. In this paper one of the inlets is referred to as a long inlet. It had an overall length of 7.1 in $(18.0 \mathrm{~cm})$. The other inlet is referred to as a short inlet and had an overall length of 5.1 in $(13.0 \mathrm{~cm})$. The long inlet had a throat radius of 5.4 in $(14.5 \mathrm{~cm})$. A photo of the long baseline inlet is shown in Figure 5.

A photograph of the scarf inlet is presented in Figure 6. As shown in the schematic of Figure 7, the scarf inlet was constructed as a combination of the long and short inlets. The transition from long side to short side is the result of numerical interpolation. In this schematic the fan blade mid chord (fan stacking point) is at the $\mathrm{x}=0.0$ position. This is a very moderate scarf inlet with a scarf angle of just $9.8^{\circ}$.

Figure 8 is a photograph of the elliptical inlet that was tested. In this picture the minor axis of the inlet is in the vertical plane. Schematics of the elliptical inlet are given in Figure 9. Parts $a$ and b show the minor and major axes of the inlet, respectively. Figure 9 also indicates that the elliptical inlet is a variation of the long baseline inlet design in that the elliptical inlet is the baseline inlet with its opposite walls folded inward toward the inlet centerline.
Inside three of the test inlets rakes were installed at various positions in order to collect aerodynamic data. No rakes were used in the long baseline inlet upstream of the rotor; however, the short inlet, scarf inlet, and the elliptical inlet were tested with two rakes upstream of the rotor. The rakes were separated by $90^{\circ}$ and located at $0.17 \mathrm{D}$ forward of the rotor face.

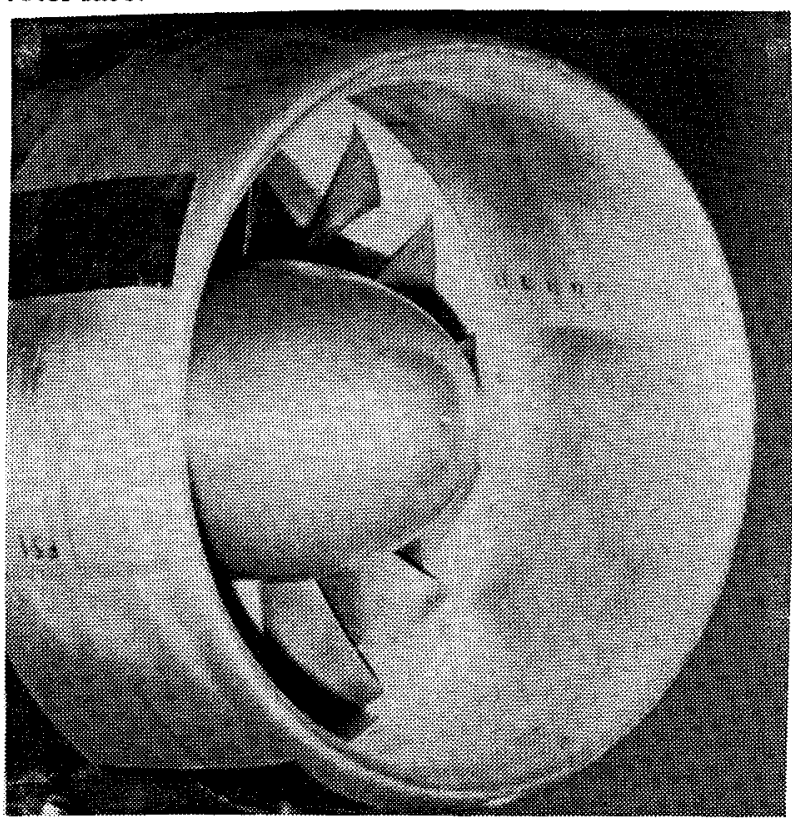

Figure 5. Photo of long baseline inlet.

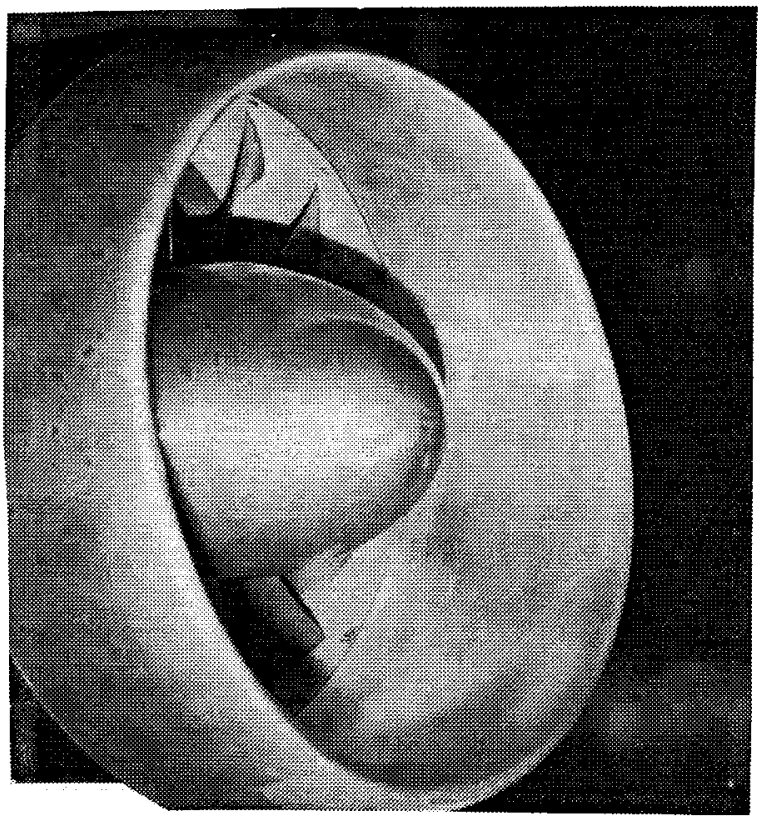

Figure 6. Photo of scarf inlet. 


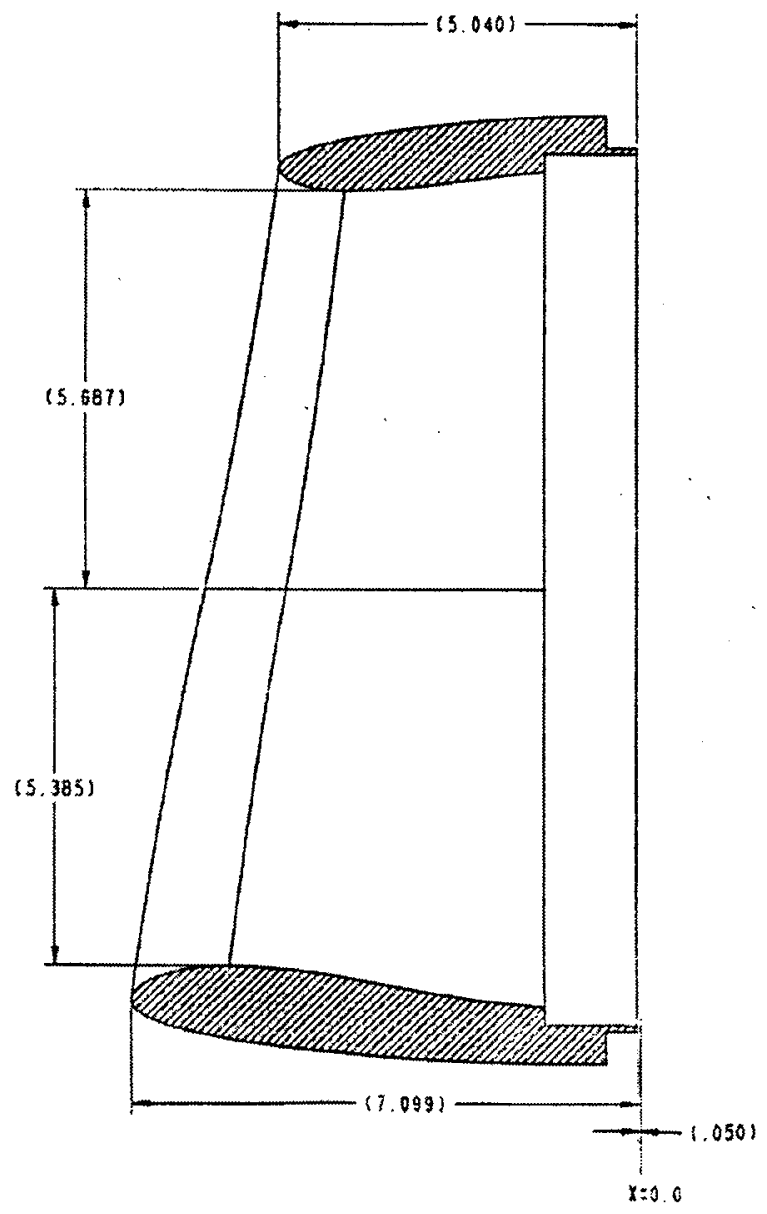

Figure 7. Schematic of scarf inlet (Dimensions are in inches.).

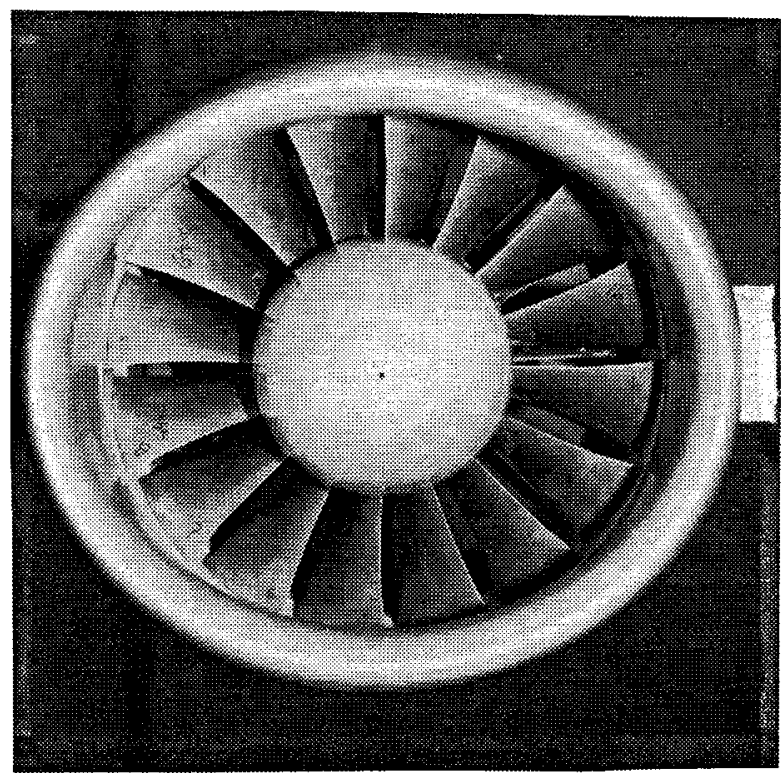

Figure 8. Photo of elliptical inlet.

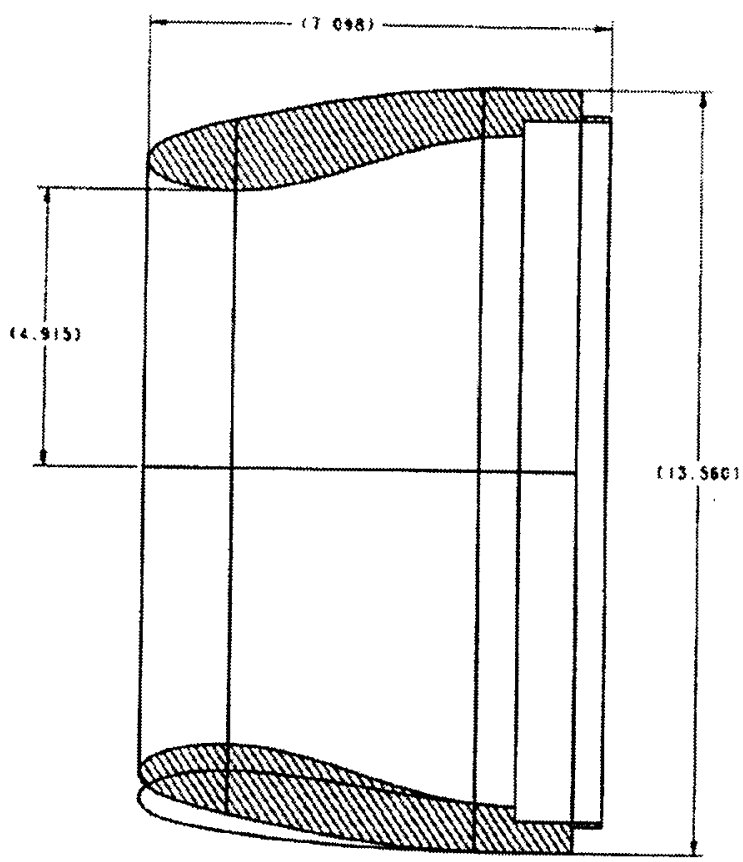

a. Elliptical inlet with minor axis highlighted.

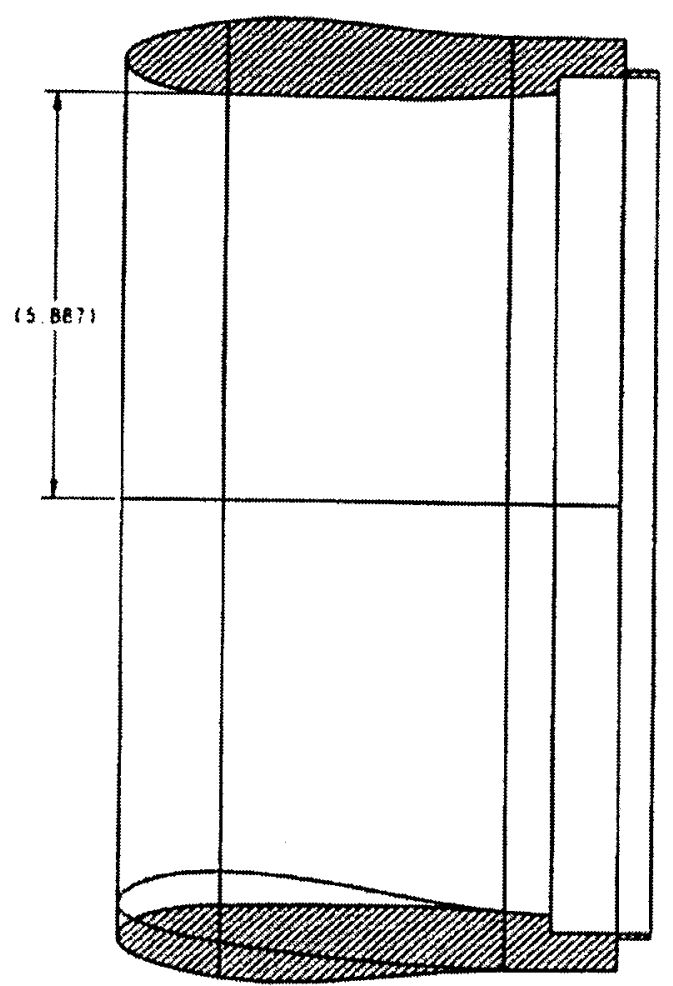

b. Elliptical inlet with major axis highlighted.

Figure 9. Schematics of elliptical inlet. (Dimensions are in inches.). Long inlet contour shown in contrast. 


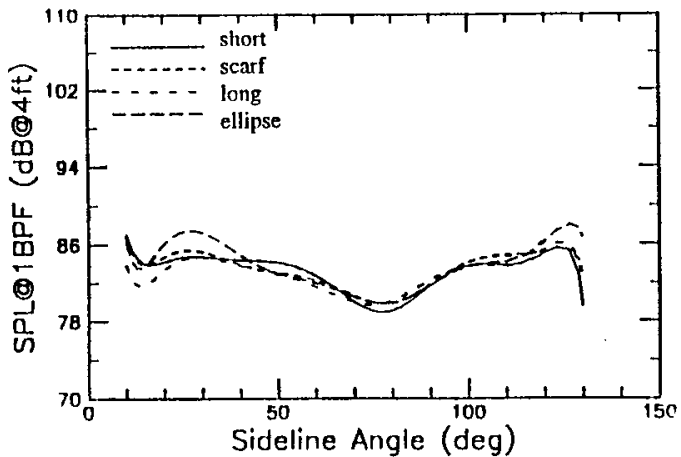

a. 1BPF

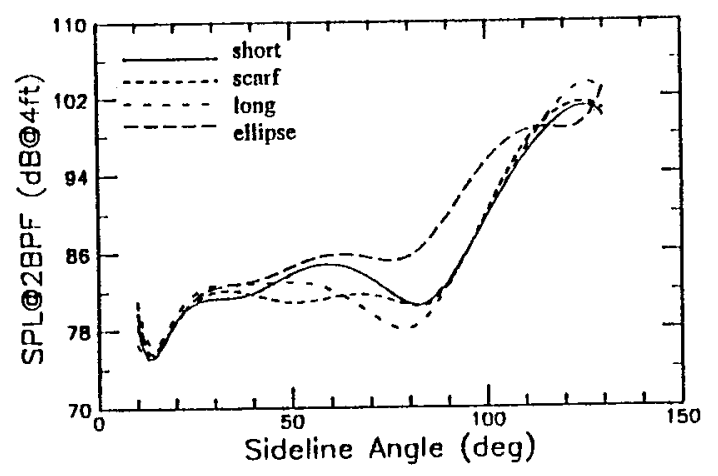

b. 2BPF

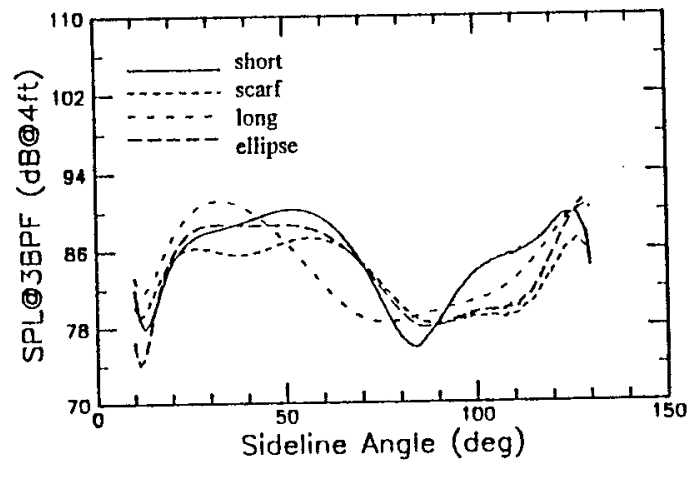

c. 3BPF

Figure 10. Sideline angle directivity plots for each test inlet, at fan speed of $70 \%$.

\section{Tone Results}

Directivity plots for the four inlets (long and short baseline inlets, scarf inlet, elliptical inlet) are presented in Figure 10. Parts $a, b$, and $c$ give sound pressure level (SPL) as a function of sideline angle for 1BPF (Blade Passage Frequency), 2BPF, and 3BPF tones, respectively. For these data comparisons the extended side of the scarf inlet was beneath the fan axis in order to direct noise away from the boom microphones. In the case of the elliptical inlet the major axis was in the horizontal plane. These orientations for the two inlets are refered to as $0^{\circ}$ orientations because they would probably be the prefered orientation of these inlets. However, both the scarf and the elliptic inlets could be oriented differently. The scarf was also tested in an orientation rotated $180^{\circ}$ which placed the long side of the inlet on the top of inlet which would direct the radiated noise downward. The ellipse was also tested in a $90^{\circ}$ rotated configuration which would place the major axis in the verical direction. These data are available but not reported here.

It should be mentioned that the plots in Figure 10 were generated by curve fitting the data obtained with the fifteen boom microphones. The decision to curve fit the data resulted from the observation that when noise measurements from all fifteen microphones are plotted for a particular sideline angle, noise variation with azimuthal angle, $\alpha$, is generally significant. To facilitate comparision of the test data, a polynomial curve fit application was used to give mean sideline plots of the BPF tones. The curve fit was done on the pressure data before converting to decibel scale. More detailed information on the azimuthal patterns which are present in the far field and the process of curve-fitting the far field data to yield one line versus sideline angle can be found in references 6 and 9 .

As indicated by each part of Figure 10, the curves associated with the four inlets exhibit a characteristic feature, namely, a major peak below $90^{\circ}$ that is dominated by the fan inlet and a major peak above $90^{\circ}$ that is influenced by the fan exhaust. In addition, Figure 10a shows that the 1BPF tone is relatively insensitive to inlet shape. The minor exception to this is at the small sideline angles. In the range $20^{\circ}$ to $30^{\circ}$ the elliptical inlet is 3 to $4 \mathrm{~dB}$ louder than the other inlets.

Figure $10 \mathrm{~b}$ shows a noticeable deviation from the foregoing result at $2 \mathrm{BPF}$. That is, the $2 \mathrm{BPF}$ tones are affected by inlet shape to an appreciable extent. At the intermediate sideline angles $\left(45^{\circ}\right.$ to $80^{\circ}$ ) both the long inlet and the scarf inlet have lower 2BPF levels. The noise reduction with the quieter inlets is generally 2 to $3 \mathrm{~dB}$. In this set of comparisons the elliptical inlet, again, has the highest levels. The elliptical inlet is as much as $5 \mathrm{~dB}$ louder than the short inlet in the sideline angle range $30^{\circ}$ to $110^{\circ}$.

The data in Figure 10c give results for the 3BPF tone. They also show that inlet shape is a factor where inlet noise is concerned. With regard to noise reduction it is the scarf inlet that performs best at relatively small sideline angles; at angles ranging from $45^{\circ}$ to $75^{\circ}$ it is the long inlet that produces the lowest noise levels. At the upper end of the sideline angle range the long inlet, the scarf inlet, and the elliptical inlet have lower levels than the short, agressive inlet. For this range of angles, it is again the scarf that is quietest.

American Institute of Aeronautics and Astronautics 
The data for each of the three tones was integrated over the entire measurement plane to yield an integrated power level, in decibels. This was done for each inlet and the results are presented in Table 1. This allows the net effect of the inlet shape over the entire measured footprint of the fan to be quantified for each tone. The results of Table 1 show that for all three tones the inlets are ordered the same form lowest to highest levels. The short inlet has the lowest level followed by the scarf and long inlets with the elliptical inlet the highest. It is observed that the scarf inlet has a sound level for all tones between that of the short inlet and that of the long inlet. In fact, the scarf inlet was designed by combining the contours of the short and long inlets.

Inlet length and shape are obviously factors in creating significant effects on all three tones. One mechanism by which the inlet length and shape can create an interaction mechanism is the inlet's boundary layer. The boundary layer - rotor interaction is a plausible mechanism. The boundary layer thickness for each inlet is included for this reason in Table 1. The thickness values are a combination of measured and estimated values. The measured values were taken just upstream of the fan leading edge. The values actually measured were a thickness of 0.08 in. for the short inlet at a speed of $93 \%$, this was scaled with speed to 0.06 in. at $70 \%$ speed based on values for the short side of the scarf inlet which were taken at $70 \%$ and at $90 \%$. The scarf inlet was measured on the long inlet side at 0.08 in. The value from the short inlet would be a good estimate for the thickness on the short side of the scarf; therefore, the thickness varies from 0.06 to $0.08 \mathrm{in}$. for the scarf inlet. A value of boundary layer thickness was not measured for the long inlet; however, the measured value for the long side of the scarf inlet should be a good estimate. The values for the elliptical inlet were both measured, one on the major axis, with the smaller thickness, and the one on the minor axis, with the much longer thickness because of the very steep diffusion angle.

Two factors are clear with the boundary layer thickness data, the first is the correlation of boundary layer thickness with inlet length and the second is the nonuniform boundary layer introduced by the nonaxisymmetric scarf and elliptical inlets. Both are plausible mechanisms to impact the tone noise levels. The short inlet with the smallest boundary layer thickness which is also uniform has the lowest tone levels. The elliptical inlet with most nonuniform and thickest boundary layer has the highest tone levels.

These results are opposite to those reported by Woodward, et. al. ${ }^{10}$ where a long and a short inlet were tested. It was found that the long inlet was lower in
BPF and 2BPF levels. This was reported for a speed range from about $75 \%$ to $107 \%$. However, there are some difficulties in comparing the results from the Woodward to those reported here. The results in Woodward are based on a maximum forward quadrant tone level and was measured by a single sideline microphone as opposed to the net value reported here integrated over 15 sideline microphones. Also, Woodward gives no information on boundary layer thickness. The possible explanations raised by Woodward are given as unknown rotor inflow disturbances and possible changes in inlet modal release dynamics.

Table 1. Boundary layer thickness (in inches) and integrated power level (in $\mathrm{dB}$ ) over the measurement area for all four inlets.

\begin{tabular}{|l|l|l|l|l|}
\hline Inlet & $\begin{array}{l}\text { Boundary layer } \\
\text { thickness range } \\
\text { (in.) }\end{array}$ & 1BPF & 2BPF & 3BPF \\
\hline short & est. 0.06 & 105.4 & 113.1 & 109.2 \\
\hline scarf & est. $0.06-0.08$ & 108.5 & 116.5 & 111.0 \\
\hline long & est. 0.08 & 110.2 & 118.6 & 112.8 \\
\hline elliptical & $0.05 \rightarrow 0.14$ & 111.6 & 120.1 & 114.1 \\
\hline
\end{tabular}

\section{Broadband Results}

Even with the model fan at the approach speed of $70 \%$ the broadband noise of the fan is still more than $20 \mathrm{~dB}$ above the background wind tunnel noise at the test condition of Mach 0.1. Therefore, broadband results were obtained for all four inlets. In addition, the experimental results were predicted by a ray acoustics method and compared to the experiments.

Ray acoustics is expected to be accurate for medium to high frequency broadband noise. ${ }^{11}$ To compare the directivity effects of the inlets with ray acoustics predictions, the data were first analyzed into one-third octave bands with center frequencies of 315$25,000 \mathrm{~Hz}$. The lowest frequency for which the inlet diameter is at least five wave-lengths is about $5500 \mathrm{~Hz}$, so ray acoustics is expected to apply to the bands with center frequencies of $6300-25,000 \mathrm{~Hz}$. 
Data
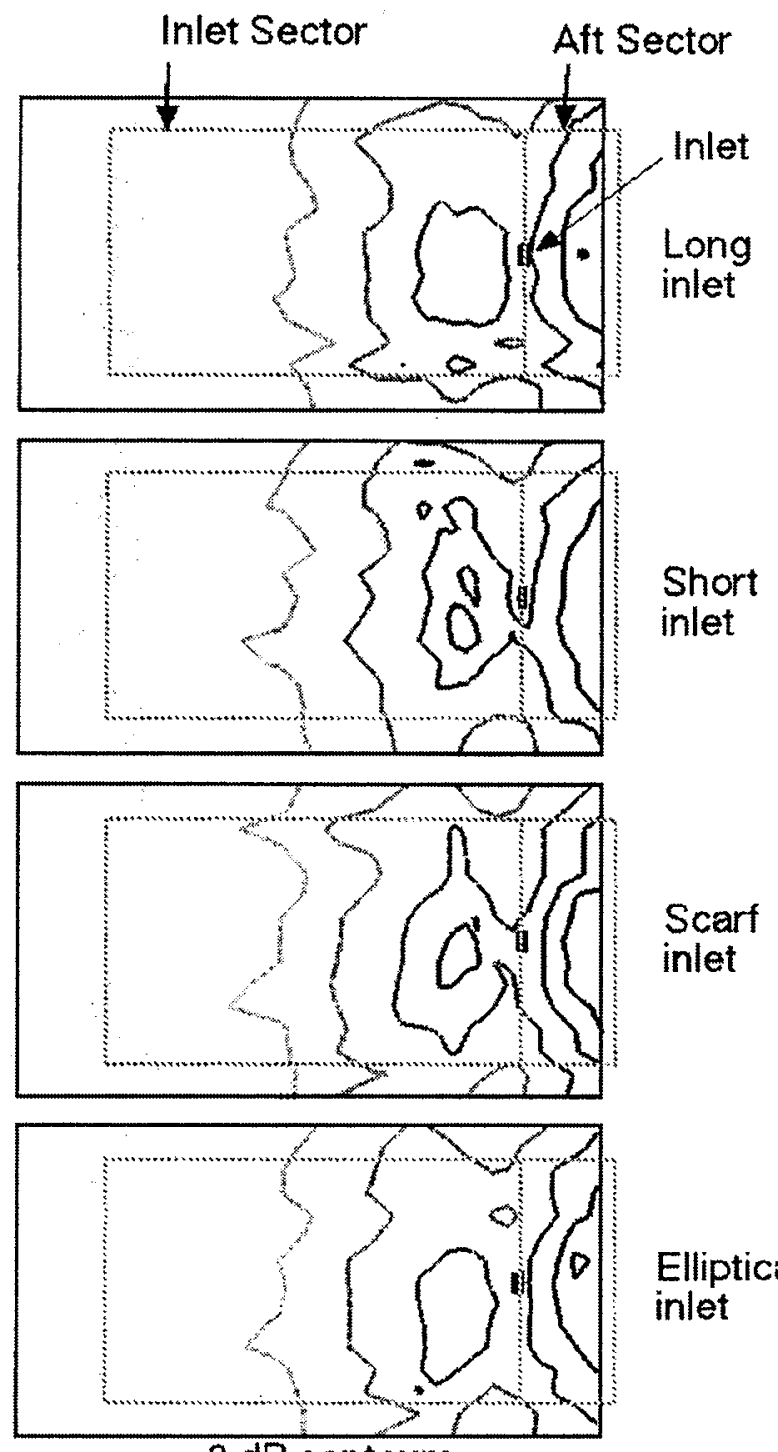

$3 \mathrm{~dB}$ contours

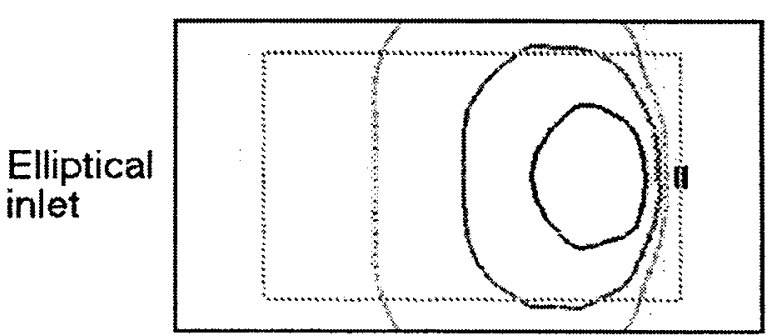

$S P L(d B)$
Ray Acoustics
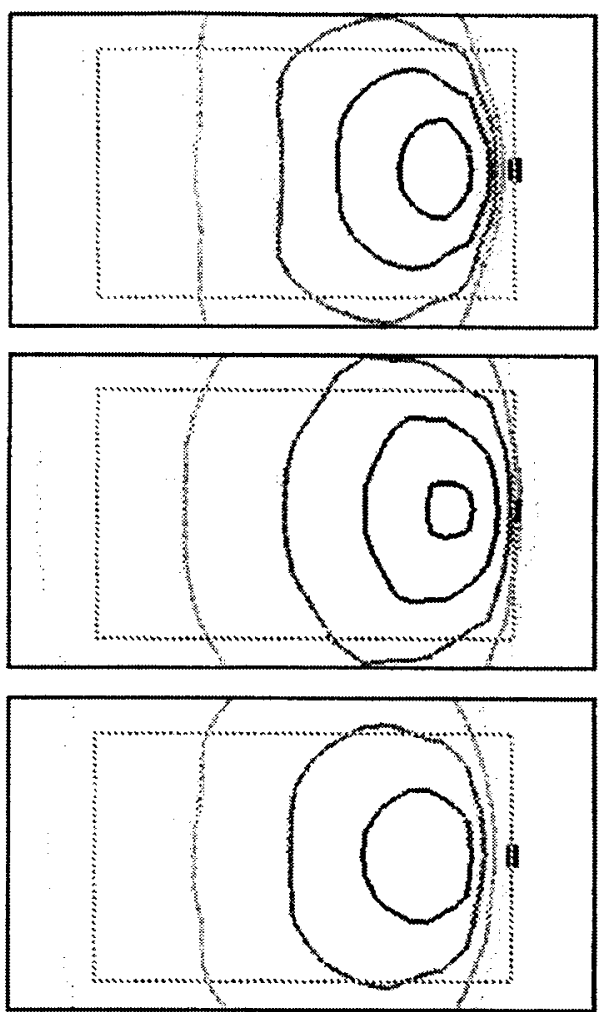

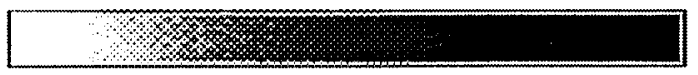

$\begin{array}{lllllll}82 & 85 & 88 & 91 & 94 & 97 & 100\end{array}$

Figure 11. Measured data and ray acoustics predictions for the four inlets in the 12,500 Hz onethird octave band. The data plots contain peaks for inlet noise (left) and aft fan noise (right). Ray acoustics predicts only inlet noise. 
Data and ray acoustics predictions for the four inlets in the 12,500 Hz band are compared in Figure 11. The data plots have two major peaks; the left peak, which corresponds to microphone positions ahead of the model, represents inlet-radiated fan noise. The peak on the right is aft fan noise. The corresponding plots for the ray acoustics have only the inlet peak, since aft-fan noise was not modeled.

Looking at the ray acoustics predictions and considering the long inlet as the baseline and comparing the other inlets with it, the short inlet has a slightly higher level and traversely wider peak, which is shifted toward the model (to the right in Figure 11). The scarf has a lower level, with the peak shifted away from the model. The peak from the elliptical inlet is very similar to the case of the scarf inlet. These trends can be seen in the data although the shifts in the data are more subtle than the predictions.

Another interesting observation is made concerning symmetry in the far field about the engine axis in Figure 11. The far field contour levels from the ray acoustics are obviously symmetrical about the engine axis. However, the experimental data shows a clear shift to the lower half of the plane of data.

To compare the inlets on a spectral basis, the array of microphone measurement points was divided into a forward sector and an aft sector, as indicated in Figure 11. For each one-third octave band, the soundpressure level data were energy-averaged over the respective sectors to produce estimates of the inlet and aft radiated noise, weighted by the distribution of the measurement points. The band centered at $6300 \mathrm{~Hz}$ was omitted to avoid a strong tone associated with the drive turbine. The resulting spectra are shown in Figure 12a.

The spectra show two peak frequencies for both aft and inlet noise, one at low frequencies and the second at $8000-10000 \mathrm{~Hz}$. Figure $12 \mathrm{~b}$ establishes the long inlet as the baseline and plots the relative values of the other inlets as compared to the long inlet. In the mid frequency range the order from lowest levels to highest is the short inlet followed by the scarf, long, and elliptical. This is the same order as was noticed in the tone data although no connection is clear. In the high frequency range, $5000-16,000 \mathrm{~Hz}$, the scarf is the inlet with the lowest level followed by the ellipitical inlet, the long and short. This trend is predicted by the ray acoustics in Figure 12d, though not quite as strongly.

The trends of the ray acoustics predictions shown in Figure $12 \mathrm{~d}$ should be noted because the real efforts of boundary layer thickness and nonuniformity among others is neglected. The ray acoustics does show the scarf as the lowest noise level inlet by about $1 / 2 \mathrm{~dB}$. Also, the elliptical inlet does have a small positive advantage over the long inlet. All three of these inlets have a larger lip radius than the short inlet which has about $1 \mathrm{~dB}$ higher level than the long inlet. The lip radius apparently accounts for some of the effects that are seen. ${ }^{12,13}$

\section{Conclusions}

An acoustic study of the effect of inlet shape has been conducted on the NASA Langley 12-inch ADP fan at a free stream Mach number of 0.1 in the NASA Langley 14-x 22-Foot Wind Tunnel. Four inlets were tested. Two were axisymmetric inlets of different length, a long standard flight-type inlet and a short more agressive inlet design. Two non-axisymmetric inlets were also tested; one was a scarf inlet set at a relatively moderate scarf angle of $10^{\circ}$ and the second inlet was elliptical in shape.

The fundamental blade passage tone and the first two harmonic tones were all sensitive to inlet shape; however, the first two harmonic tones were especially sensitive. The sideline directivity could be affected by up to $8 \mathrm{~dB}$ by the inlet shape. Using integrated sound levels over the entire measured plane the short inlet had the lowest level for all three tones followed by the scarf, the long, and the elliptical with the highest tone levels. It is possible that both the level and the nonuniformity of the boundary layer thickness are key mechanisms, when interacting with the rotor, in the generation of the tone levels measured. In the design of a nonaxisymmetric inlet, the effect of the boundary layer should be well understood and taken into consideration.

The effect of inlet shape on broadband data is frequency dependent. In the high frequency range, 5000 to $16,000 \mathrm{~Hz}$, the levels of broadband noise from lowest to highest are produced by the scarf inlet, then the elliptical inlet followed by the long and short inlets. The benefit of the scarf and elliptical inlets comes from the simple shielding effect, accomplished in two different ways. The maximum benefit is small, about $1 / 2 \mathrm{~dB}$, for the scarf inlet; however, it should be noted that this scarf had a very modest scarf inlet angle. A more aggressive, well designed scarf inlet should produce significantly better results.

\section{Acknowledgements}

The authors extend sincere appreciation to Larry Becker, Charlie Smith, and Dave DeVilbiss of Lochkeed-Martin for their contributions to the acoustic data axquisition, and to mark Cagle of the Model Instrumentation and Systems Branch for help with design of the scarf and elliptical inlets. The authors also 
thank Brenda Gile Laflin of the Subsonic Aerodynamics Branch for liason with the 14- by 22-Foot Subsonic Tunnel. R. H. Thomas also gratefully acknowledges the support of the Aeroacoustics Branch of NASA Langley Research Center.

\section{References}

1. Abbott, J.M., and Dietrich, D.A., "Aerodynamic and Directional Acoustic Performance of a Scoop Inlet," NASA TP 1028, September 1977.

2. Abbott, J.M., "Aeroacoustic Performance of a Scoop Inlet," NASA TM 73725, October 1977.

3. Silcox, R.J., "Geometry and Static Flow Effects on Acoustic Radiation from Ducts," AIAA Journal, Vol. 22, No. 8, August 1984, pp. 10871093.

4. Peake, N., "A Theoretical Investigation of the Noise Radiation from a Scarfed Intake," CEAS/AIAA Paper 95-101, June 1995.

5. Hodges, R.M., Gerhold, C.H., Balster, D., and Thomas, R.H., "Acoustic Testing of Very High Bypass Ratio Turbofans Using Turbine Powered Scale Models," AIAA Paper 94-2552, presented at 18th AIAA Aerospace Ground Testing Conference, June 20-23, 1994.

6. Thomas, R.H., Gerhold, C.H., Farassat, F., Santa Maria, O.L., Nuckolls, W.E., and DeVilbiss, D.W., "Far Field Noise of the 12 Inch Advanced Ducted Propeller Simulator," AIAA Paper 95-0722, January 1995.

7. Gentry, G.L., Quinto, P.F., Gatlin, G.M., and Applin, Z.T., "The Langley 14- by 22-Foot Subsonic Tunnel: Description, Flow Characteristics, and Guide for User," NASA TP 3008, 1990.

8. Preisser, J.S., Schoenster, J.A., Golub, R.A., Horne, C., "Turbofan Engine Blade Pressure and Acoustic Radiation at Simulated Forward speed," Journal of Aircraft, Vol. 20, No. 4, pp. 289-297, April 1993.

9. Thomas, R.H., Farassat, F., Clark, L.R., and Gerhold, C.H., "Azimuthal Patterns of the Radiated Sound Field from a Turbofan Model," AIAA Paper 97-1588, presented at the 3rd
AIAA/CEAS Aeroacoustics Conference, May 1214, 1997.

10. Woodward, R.P., Bock, L.A., Heidelberg, L.J., and Hall, D.G., "Model Ducted Propulsor Noise Characteristics at Takeoff Conditions," Journal of Aircraft, Vol. 31, No. 5, Sept-Oct., 1994.

11. Dougherty, R.P., "Nacelle Acoustic Deisgn by Ray Tracing in Three Dimensions," AIAA Paper 96-1773, 1996.

12. Meyer, W.L. and Zinn, B.T., "A Parametric Study of the Effect of Inlet Lip Shape Upon the Radiated Sound Field," AIAA Paper No. 840498, 22nd Aerospace Sciences Meeting, Reno, NV.

13. Baumeister, K.J., "Utilizing Numerical Techniques in Turbonfan Inlet Acoustic Suppressor Design," NASA Technical Memorandum 82994, 1982. 
a.

Absolule dala

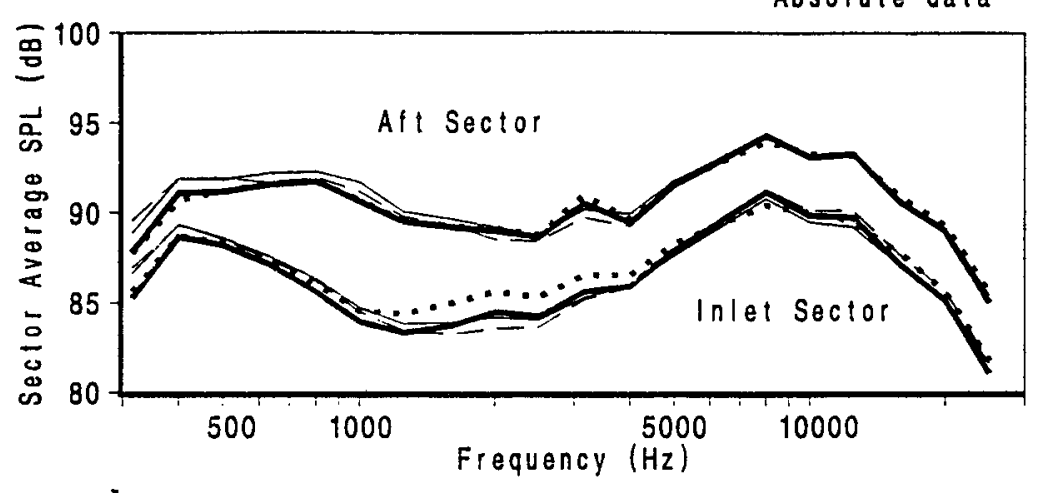

Long

- - Short

Scarf

..... Elliptical

(0 deg.)

b.

Inlet sector data re. long inlet case

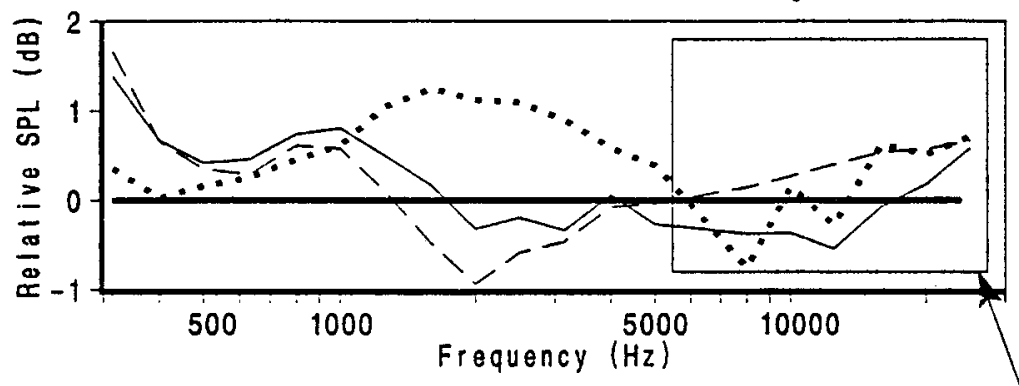

c.

Aft sector data re. long inlet case

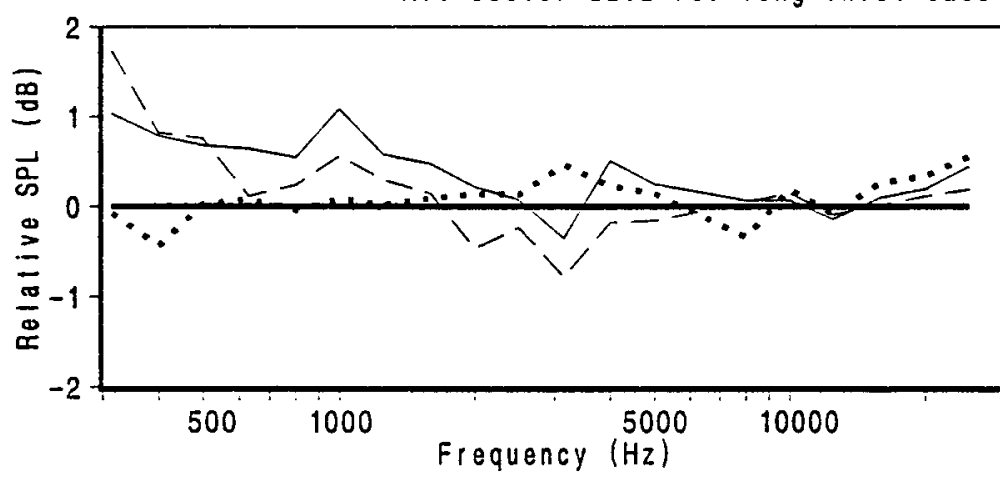

d.

Ray acoustics prediction for inlet sector re. long

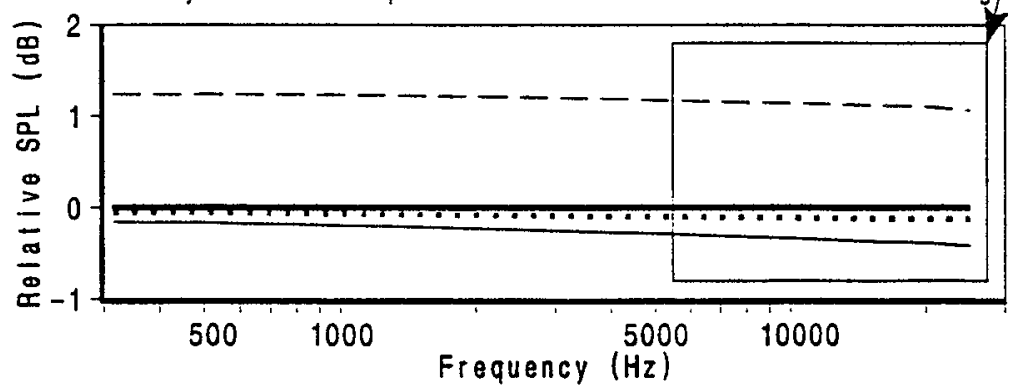

Comparison

between

data and

ray acoustics

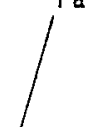

(19)

Figure 12. One third octave band inlet and aft sector noise for the four inlets, a. absolute experimental data, $b$. inlet sector noise for the short, scarf, and elliptical inlets relative to the long inlet case, $c$. aft sector noise for the three inlets relative to the long inlet case, and d. ray acoustics predictions corresponding to the boxed portion of the experimental data in part $b$. 
